\title{
Dossî́
}

\section{O professor entusiasmado: deslindando o DNA de uma espécie ameaçada de extinção}

\author{
Sonia Carvalho Leme Moura Véras ${ }^{1}$ \\ Cristiane Faiad de Moura ${ }^{2}$ \\ Jaqueline Fonseca Rodrigues ${ }^{3}$ \\ Tatiana Farias Moreira ${ }^{4}$ \\ José FlorênCIO Rodrigues JúNioR ${ }^{5}$
}

Resumo: O estudo do entusiasmo docente, cuja origem se situa aproximadamente na década de 1950, põe em destaque os gestos como um indicador daquele construto. Neste texto, serão revistos estudos categorizados como experimentais e expost facto, os quais se propõem a dar contornos ao construto entusiasmo docente. Por outro lado, modificando o curso de exploração sobre o entusiasmo docente, procurou-se estabelecer uma proposição por meio da qual o entusiasmo manifesto por professores universitários deve ser visto como tendo sua origem nas camadas profundas da natureza humana, e não na exterioridade do gesto. Esse posicionamento assenta-se sobre argumentos de três ordens: (1) etimológica, (2) filosófica e (3) empírica. Esse último argumento, por sua vez, desvela três fatores na constituição do professor universitário entusiasmado: (1) respeitoso e sábio, (2) comprometido e exigente e (3) informal.

Palavras-chave: Entusiasmo docente. Gestos. Professores universitários.

\section{The enthusiastic teacher: unravelling the DNA of an endangered species}

\begin{abstract}
The study of teacher enthusiasm since the 1950 decade has highlighted the importance of gestures as an indication of that construct. In this study we review studies categorized as experimental and ex post facto, which undertook delineating the construct teacher enthusiasm. Taking a different turn, we contend that enthusiasm as a construct manifested by university faculty, should be viewed as having its origin in the deep layers of the human nature. Our stance is supported by three arguments: (1) the etymological, (2) the philosophical, and (3) the empirical. The empirical argument is founded on a study indicating that teacher enthusiasm manifested by university faculty has three factors: (1) respectful and wise, (2) committed and exigent and (3) casual. Keywords: Teacher enthusiasm. Gestures. University faculty.
\end{abstract}




\section{El profesor entusiasmado: desmarcando el ADN de una especie amenazada de extinción}

Resumen: El estudio del entusiasmo docente, cuyo origen se sitúa - aproximadamente - en la década de 1950, destaca los gestos como un indicador de aquel constructo. En este texto, revisamos estudios categorizados como experimentales y ex post facto, que buscan dar contornos al constructo entusiasmo docente. Por otro lado, modificando el curso de análisis sobre el entusiasmo docente, procuramos establecer la proposición, según la cual, el entusiasmo expresado por profesores universitarios debe verse como teniendo su origen en los sustratos profundos de la naturaleza humana y no en la exterioridad del gesto. Nuestra posición se fundamenta en argumentos de tres tipos: (1) etimológico, (2) filosófico y (3) empírico. Este último argumento, a su vez, desvela tres factores en la constitución del profesor universitario entusiasmado. Son ellos, (1) respetuoso y sabio, (2) comprometido y exigente e (3) informal.

Palabras clave: Entusiasmo docente. Gestos. Profesores universitarios.

\section{Introdução}

Este texto intenta trazer à tona o tópico entusiasmo do professor, ou entusiasmo docente, tal como ele se manifesta em professores universitários. $\mathrm{O}$ propósito é, em primeiro lugar, questionar a tradição vigente, até agora, de que o referido entusiasmo tem sua origem na postura do professor, particularmente nos gestos realizados durante a instrução.

O posicionamento funda-se sobre quatro postulados derivados de Perelman (1988). O primeiro é que a maior parte das pesquisas, tendo como foco o entusiasmo docente até o presente, situa o lócus do construto entusiasmo nos gestos. O segundo postulado é de que as pesquisas realizadas podem ser agrupadas em duas categorias: experimentais e ex post facto. O terceiro postulado aponta que a ênfase posta nos gestos como sede do entusiasmo do professor é provavelmente equivocada. Finalmente, o quarto postulado visa dirimir o equívoco do terceiro postulado mediante três linhas de argumentação: a etimológica, a filosófica e a empírica. Os quatro postulados, assim como os argumentos, constituem o arcabouço do texto.

\section{Sumário de estudos atinentes ao professor entusiasmado}

Numerosos estudos tendo o professor universitário eficiente como objeto apontam o entusiasmo como um dos seus atributos. Esses estudos remontam à década de 1950. Por exemplo, Coffman (1954) identificou por meio de análise fatorial quatro fatores que fazem parte do perfil do professor universitário eficiente (empatia, organização, pontual/boa apresentação e fluente). O entusiasmo do professor e o interesse na matéria foram duas das variáveis consideradas que 
tiveram uma representação insignificante nesses quatro fatores. Estudos mais recentes, tais como os de Li e Kaye (1998) e Onwuegbuzie et al. (2007) incluíram o entusiasmo como um atributo nos seus formulários de avaliação. Neste último estudo, entusiasmo foi definido como uma paixão pela matéria que se ensina (ONWUEGBUZIE et al., 2007). Na análise fatorial, entusiasmo teve uma carga fatorial de 0,72 no fator empoderamento (empowerment, em inglês), caracterizando instrutores universitários eficientes - carga fatorial essa significativa.

Embora entusiasmo tenha aparecido em pesquisas sobre o professor universitário eficiente desde a década de 1950, o estudo do entusiasmo como um traço distintivo e destacado de professores eficientes ocorreu somente a partir da década de 1960. Nove pesquisas foram localizadas em uma busca por meio das plataformas Web of Science e ERIC, tomando como datas-base os anos entre 1950 e 2005 e como referência a expressão "teacher enthusiasm". A busca não se restringiu às bases de dados internacionais. Procedeu-se à busca na base de dados do Instituto Brasileiro de Informação em Ciência e Tecnologia (IBICT), que abriga teses e dissertações das principais universidades brasileiras. Essa busca evidenciou que entusiasmo docente, ou entusiasmo do professor, está ausente da agenda de pesquisa dos principais centros acadêmicos nacionais dentro de espaço cronológico investigado.

\section{Paradigmas de pesquisas no estudo do professor entusiasmado}

Desde que se iniciou o estudo do entusiasmo docente, foram dois os paradigmas adotados na sua condução: o experimental e o ex post facto. A marca distintiva do primeiro paradigma é o pressuposto de que o entusiasmo docente tem atributos manifestos pelo professor entusiasmado sob a forma de comportamentos observáveis; uma vez identificados esses comportamentos, eles podem ser isolados e aprendidos por professores iniciantes, os quais, por esse procedimento, tornam-se entusiasmados no seu ensino. As pesquisas pertencentes ao paradigma ex post facto presumem a existência do entusiasmo do professor como um atributo autossuficiente, percebido pelos estudantes. As primeiras pesquisas sobre o entusiasmo docente foram realizadas em contextos de ensino fundamental. As pesquisas mais recentes têm como ambiente a educação superior. Uma amostra de estudos pertencentes aos dois paradigmas será apresentada na seção seguinte.

\section{Paradigma experimental}

Os estudos alinhados com este paradigma refletem a época em que estudos experimentais eram a norma, ou seja, punha-se ênfase na meticulosa manipulação das variáveis critério (RYANS, 1970). Uma amostra de estudos experimentais focalizando o entusiasmo docente é apresentada na sequência. 
Os sete estudos identificados nesse agrupamento são originários da América do Norte: seis dos Estados Unidos (MASTIN, 1963; YOUNG, 1973; McKINNEY et al., 1982; BETTENCOURT et al., 1983; WINEBURGH, 1990; PATRICK; HINSLEY; KEMPLER, 2000) e um do Canadá (WOOD; MURRAY, 1999). Eles foram realizados em escolas elementares, escolas de ensino médio e Instituição de Ensino Superior.

O delineamento das pesquisas é comum aos sete estudos: uma professora treinada nos fundamentos de entusiasmo e em como praticá-los em sala de aula faria demonstração aos professores a serem treinados. Entusiasmo era exposto por meio de condutas como mover-se em frente à turma durante a instrução e modular a voz. Essas condutas eram apresentadas pela professora ao vivo ou em filme. No passo seguinte, os professores treinados incorporariam as condutas inerentes ao entusiasmo em sua instrução nas turmas.

Os estudos cuja variável dependente foi aprendizagem cognitiva resultaram em diferenças não significativas, quando se compararam grupos experimental ao controle, sendo o estudo de Mastin (1963) o único a apresentar diferença significativa para o grupo experimental. Quando a variável dependente se sediava no domínio afetivo, representado por construtos como percepções, motivação, entre outros, os resultados favoreceram a condição experimental.

A evidência refletida nos estudos experimentais é de que a intervenção na instrução de sala de aula, mediante condutas presumivelmente portadoras de entusiasmo, entre elas modulação vocal, circulação no espaço da sala e gesticulação, não propicia ganhos cognitivos nos estudantes; entretanto, quando se consideram ganhos na aprendizagem afetiva, eles ficam patentes nos estudos experimentais.

\section{Paradigma expost facto}

Três estudos focalizando o entusiasmo docente foram estruturados consoante o paradigma ex post facto. Como se sabe, esse paradigma presume que a variável independente já teve sua vigência, diferentemente do paradigma experimental, no qual se busca controlar aquela variável. Os estudos referidos foram Fanchon et al. (1982), Barnes e Barnes (1993) e Murphy e Walls (1984), menos numerosos do que os estudos experimentais. Os estudos com base no paradigma expost facto são também menos homogêneos em sua constituição e em seus resultados. O foco desses estudos trata da questão dos ganhos de aprendizagem, sejam cognitivos, sejam afetivos. Eles centram-se na natureza do entusiasmo docente. Tipicamente, esses estudos empregam questionários como instrumentos de pesquisa.

A pesquisa de Fanchon et al. (1982) teve como diretriz a pergunta: "que características tipificam o supervisor educacional encorajador?". Entusiasmo foi 
uma das quatro características identificadas por meio de análise fatorial; as outras três foram encorajamento, ser agradável e desafiador. Pode-se observar que o estudo de Fanchon et al. (1982) não se endereça àquilo que, no sistema de classificação de questões de pesquisa de Dillon (1984), seria uma questão de primeira ordem. Diferentemente do estudo de Fanchon et al. (1982), aprende-se que entusiasmo é uma das qualidades do supervisor educacional encorajador.

Barnes e Barnes (1993) pesquisaram o entusiasmo docente com maior profundidade do que Fanchon et al. (1982), embora o foco da investigação tenha sido um questionário de avaliação docente e em que medida ele refletia condições subjacentes aos cursos e às disciplinas na academia. Os autores submeteram o questionário a alunos de 11 cursos da área de Humanas e 17 cursos da área de Ciências de uma universidade do centro-oeste norte-americano. $\mathrm{O}$ instrumento produzido por Barnes e Barnes (1993) foi construído com base em seis características de professores eficientes: organização da instrução, abrangência do conteúdo, interação grupal, entusiasmo, atribuição de notas e relacionamento pessoal.

A característica entusiasmo foi representada por cinco descritores: manutenção da atenção da classe, apresentações vívidas, uso de exemplos para esclarecimento, coerência na apresentação dos materiais e preparação prévia para as apresentações, que se mostraram mais úteis para avaliar professores do que cursos. Observa-se no estudo de Barnes e Barnes (1993) que os descritores de entusiasmo têm nuances acentuadamente cognitivas, por exemplo, "uso de exemplos para esclarecimento", diferentemente daqueles utilizados por McKinney et al. (1982), por exemplo, "gestos" e "expressões faciais", cuja natureza é acentuadamente enativa.

Ao examinar o estudo de Murphy e Walls (1984), o terceiro dos estudos expost facto, ressalta-se sua natureza peculiar. De fato, não se trata de um estudo experimental, uma vez que não ocorre uma intervenção presumindo controle sobre variáveis independentes. Por outro lado, os participantes da pesquisa observaram vídeos de quatro excelentes professores com o objetivo de determinar a ocorrência ou não de cinco comportamentos indicadores de entusiasmo e se eles ocorriam sequencial ou simultaneamente. Em vista da natureza híbrida desse estudo, ele foi colocado na categoria ex post facto. Os cinco comportamentos aludidos foram: (1) contato visual, (2) expressão facial, (3) modulação vocal, (4) gesticulação e (5) movimentação. Os quatro instrutores estavam em salas de aula ordinárias, e os segmentos gravados em vídeo tiveram a duração de 30 minutos.

Murphy e Walls (1984) procederam a várias combinações dos cinco comportamentos indicativos de entusiasmo docente. Destacam-se duas: os dois comportamentos mais ocorrentes concomitantemente foram contato visual e modulação vocal; e, considerando comportamentos sequencialmente, a maior frequência foi modulação vocal, seguida de gesticulação e de movimentação. Traduzindo em termos práticos, o instrutor entusiasmado utilizaria com mais 
frequência o binômio contato visual e modulação vocal simultaneamente. Ele começaria sua instrução com esses mesmos comportamentos, acrescentado a eles gesticulação; após pôr em prática esses três comportamentos, o instrutor entusiasmado se movimentaria pelo espaço da sala de aula.

\section{Estudos recentes sobre o entusiasmo docente}

A década de 2010 marca a retomada do interesse de pesquisadores pelo professor entusiasmado. Desde então e até o presente, numerosos pesquisadores encetaram investigar o entusiasmo docente utilizando uma pluralidade de metodologias; sobretudo, novas ferramentas da estatística foram utilizadas na análise de dados. Outro traço dessa retomada do interesse pelo estudo do assunto é o deslocamento do cenário da América do Norte para a Europa. Nesta seção, serão apresentados achados resultantes de pesquisas, particularmente nas duas últimas décadas.

Foram incluídos três estudos: o de Kunter et al. (2011), originário da Alemanha, o de Orosz et al. (2015), procedente da Hungria, e o de Keller et al. (2015), com participação de pesquisadores da Áustria, da Alemanha e dos Estados Unidos. Os três estudos utilizam a metodologia expost facto, valendo-se extensamente de questionários respondidos tanto por professores como por alunos.

O primeiro estudo detecta, mediante análise fatorial confirmatória, a existência de dois fatores no entusiasmo docente (KUNTER et al., 2011): (1) entusiasmo por ensinar e (2) entusiasmo pelo assunto ensinado. $O$ entusiasmo docente do primeiro tipo consiste em uma orientação afetiva por parte do professor entusiasmado, a qual tem sua origem no prazer que ele sente em ministrar a instrução. Por sua vez, o entusiasmo pelo assunto ensinado deriva da matéria que esse professor leciona. São manifestações muito próximas, de difícil distinção, porém que têm efeitos distintos sobre o aluno. Segundo informa o estudo de Kunter et al. (2011), professores movidos pelo entusiasmo por ensinar promovem motivação e engajamento dos estudantes, manifestados tanto no modo como participam da instrução como no baixo índice de indisciplina. Dessa maneira, essa reciprocidade desses dois agentes torna-se fundamental em salas de aula de professores entusiasmados por ensinar, condição sem proeminência em salas de aula de professores entusiasmados pelo assunto que ensinam.

O segundo estudo contemporâneo sobre o professor entusiasmado, como indicado, provém de pesquisadores húngaros. A hipótese de trabalho deles foi de que o professor entusiasmado desestimula a cola na sua sala de aula. Essa hipótese foi construída com base no pressuposto de que o professor entusiasmado motiva os alunos, os quais, nessa condição, têm menor disposição para colar nos seus exames. Os dados, provenientes de questionários administrados a universitários daquele país, deram suporte à relação hipotetizada (OROSZ et al., 2015). 
Sem dúvida, o estudo de maior relevância, entre os três, em desvelar a natureza e a constituição do entusiasmo docente é o de Keller et al. (2015). A importância desse estudo decorre de ser ele uma ampla revisão de estudos sobre o professor entusiasmado, abrangendo um intervalo de 45 anos, totalizando 63 fontes em condições válidas de revisão.

Nessa revisão de literatura, Keller et al. (2015) chegaram a algumas proposições fundamentais: primeira, eles estabeleceram como alicerce que o entusiasmo docente é um construto afetivo-emocional; segunda, eles distinguiram no entusiasmo docente duas vertentes, o entusiasmo vivenciado e o manifesto. $\mathrm{O}$ primeiro tipo caracteriza-se pelo prazer e excitamento que o professor entusiasmado experimenta no exercício da função docente; o segundo, por condutas observáveis do professor entusiasmado, particularmente quando conduz a instrução em sala de aula. Essas condutas são numerosas e variam conforme os pesquisadores que se detêm em estudá-las, por exemplo, animação vocal, movimentos corporais e deslocamento no espaço da sala de aula. Condutas indicativas do entusiasmo docente são úteis no estudo do construto; entretanto - e nesse aspecto os autores do presente texto concorrem com os europeus -, reduzir o entusiasmo docente a condutas observáveis é o mesmo que deter-se nas árvores perdendo-se de vista a floresta.

Uma terceira proposição oriunda do trabalho de Keller et al. (2015) é que o entusiasmo docente necessita de eco, ou seja, o entusiasmo docente não acontece no vácuo. É necessário que haja alunos responsivos, engajados na e com a instrução para que haja um professor entusiasmado. Essa proposição dos pesquisadores austríacos converge com o que o presente grupo de pesquisadores verificou mediante entrevistas com professores entusiasmados. Esses professores indicaram que dependem da reciprocidade dos seus alunos (SOUZA et al., 2014).

O último aspecto a destacar no trabalho de Keller et al. (2015) é que tentar treinar professores a se tornarem entusiasmados com base em condutas observáveis (entusiasmo manifesto) equivale a prestar atenção aos efeitos do construto, e não às suas causas (entusiasmo vivenciado).

\section{Uma nova abordagem na pesquisa sobre o professor entusiasmado}

Os estudos revisados na seção anterior delinearam uma vasta constelação de pressupostos e componentes do construto entusiasmo docente. Entretanto, a despeito da complexa malha de elementos apresentados, o professor entusiasmado como objeto de pesquisa ainda instiga a curiosidade de pesquisadores. No caso presente, motivou a examinar componentes ausentes nas pesquisas anteriores, em particular aspectos da subjetividade desse professor sugeridos pelas perspectivas filosófica, teológica e psicológica do entusiasmo. Essas três perspectivas convencem de que é necessário descer a subterrâneos mais profundos do construto a fim de explorar veios tão ricos quanto os desvelados até o presente. 
O entusiasmo docente vai além dos gestos: três argumentos

Explicita-se a razão de o construto entusiasmo ser posto em uma perspectiva mais ampla do que os gestos são capazes de caracterizar. Assim, vale-se de três argumentos: o etimológico, o filosófico-teológico e o empírico.

\section{O etimológico}

É importante chamar a atenção para a etimologia do termo "entusiasmo". A palavra grega combina a preposição $\varepsilon v$ (no interior) e o substantivo $\theta \varepsilon o \varsigma$ (deus) (ARNDT; GINGRICH, 1959). Consequentemente, na sua origem, entusiasmo é um atributo de uma pessoa anfitriã da divindade. Uma visão semelhante de entusiasmo é oriunda de Webster: "emoção forte ou sentimento por uma causa; zelo ou interesse ardente e criativo; fervor" (NEILSON, 1947). Portanto, a etimologia de entusiasmo orienta para a busca da subjacência do indivíduo. Assim, focalizar somente os gestos indica que equivocadamente conclusões são tiradas a partir de efeitos, em vez de sua origem ou sua causa.

\section{O filosófico-teológico}

A partir de uma análise etimológica de entusiasmo, o entendimento dos filósofos do século XVIII em diante reforça a visão de que o citado construto deriva de estruturas e dinâmicas subjacentes à natureza humana. Contudo, embora atribuindo a gênese do entusiasmo a estruturas profundas da natureza humana, os filósofos referidos não têm uma postura favorável sobre ele. Ao contrário disso, o entusiasmo é tido como uma característica suscetível à manipulação.

O conde Shaftesbury (1999), por exemplo, associa o entusiasmo ao humor, mas de forma negativa. Para ele, bom humor vincula-se à religião autêntica, enquanto o mau humor, ao ateísmo. Por outro lado, o entusiasmo destoa da religião autêntica: "O bom humor não é somente uma boa garantia contra o entusiasmo, mas o melhor fundamento da piedade e da religião autêntica" (SHAFTESBURY, 1999, p. 16). Para Shaftesbury (1999, p. 10), a melancolia provoca a paixão e a imaginação, redundando em entusiasmo: "A melancolia se faz acompanhar do entusiasmo. Seja ele proveniente de amor ou religião (porque há entusiasmo em ambos)".

O filósofo escocês Hume (1964) concorda com Shaftesbury acerca da postura negativa em relação ao entusiasmo. Ele adverte seus leitores acerca da associação entre entusiasmo e superstição, gerando farsa/falsidade e fanatismo (HUME, 1964). Diferentemente de Shaftesbury, Hume demonstra reservas acerca da religião. Ele enxerga um concubinato entre religião e entusiasmo nocivo à 
moralidade: "mas, onde os interesses da religião estiverem presentes, nenhuma moralidade pode ser imposta a um fervoroso entusiasta" (HUME, 1964, p. 462). Concomitantemente aos filósofos desse período, teólogos também se pronunciaram com respeito do entusiasmo. Esse é o caso de Taylor, o qual publicou "História Natural do Entusiasmo", em 1842. Um reputado erudito no estudo da Bíblia, da Teologia e da História do Cristianismo, Taylor chamou para si a tarefa de desmantelar e denegrir o entusiasmo cultivado e praticado por indivíduos e grupos do protestantismo e catolicismo do seu tempo. Embora discordando de Hume, seu contemporâneo, um agnóstico professo, Taylor concorda com ele no tocante aos danos causados pelo entusiasmo ao exercício da piedade e da fé cristãs: "Um temperamento ardente converte um entusiasta num zelote" (TAYLOR, 1834, p. 12).

Kierkegaard (1968), filósofo e teólogo dinamarquês do século XVIII, refere-se ao entusiasmo como uma condição da mente e do espírito, ora louvável, ora nociva. Como outros filósofos e teólogos dos séculos precedentes, Kierkegaard associa entusiasmo com melancolia. Em uma nota autobiográfica, ele escreveu (1968, p. 113):

Desde a idade tenra destinado a uma vida agonizante que poucos poderiam jamais imaginar, arremessado na mais profunda melancolia, e por esta ao desespero, vim a entender-me por meio da escrita. Consegui compreender a mim mesmo por meio da escrita. A origem do entusiasmo foi a ética. Ai de mim, eu estava em agonia para realizar a perfeição por causa da minha infelicidade que me afastava do resto da humanidade.

Possivelmente o tratamento mais extenso e profundo dado ao entusiasmo pelo ângulo da Teologia seja a obra de Knox, "Enthusiasm: A Chapter in the History of Religion" (1950). Knox despendeu 30 anos em escrevê-lo, concentrando-se em movimentos religiosos dos séculos XVIII e XIX, nos quais o entusiasmo foi uma característica proeminente. Líderes de numerosos movimentos religiosos compartilhavam de condutas a um só tempo de mistificação e piedade como se fossem irmãs siamesas. Durante os cultos aconteciam aberrações de conduta - por exemplo, jogarem-se ao chão espumando como em um ataque epiléptico ou despirem-se -, ações essas justificadas pela liberdade conferida pelo espírito.

Porém Knox, diferentemente de Shaftesbury, Hume e Taylor, não emitiu um juízo depreciativo sobre o entusiasmo imanente naqueles movimentos religiosos e outros. Ele se confessou perplexo sobre como o Eterno, a despeito de toda a fragilidade e perfídia humanas, podia realizar obras extraordinárias. No final de sua obra, ele arremata: "But my aim is to interpret enthusiasm, not to criticize it. If we would interpret it rightly, there is one point that must be seized on above all the rest - in itself enthusiasm is not a wrong tendency but a false emphasis" (1950, p. 590). 
Finalmente, uma contribuição da literatura de ficção resume o entusiasmo gerado, nutrido e expandido naquele que é, possivelmente, seu ambiente mais propício: a religião. Sinclair Lewis (1927) criou um personagem que dá o título à sua obra - Elmer Gantry -, um misto de rufião e beato.

A obra de Lewis materializou-se no cinema com o título de mesmo nome, traduzido para o português como "Entre Deus e o Pecado" (1960). Um belo tipo, voz envolvente e treino como caixeiro-viajante, Gantry (representado magistralmente por Burt Lancaster) cai como um raio no meio de um movimento revivalista americano no centro-oeste americano e, valendo-se da boa-fé da audiência, como da conivência da profetisa Falconer (estrelada de modo igualmente magistral por Jean Simmons), arrebata, enleva, promove conversões e curas. Arrecada dinheiro com a facilidade e eficiência de um vendedor. Sua fala e suas ações constituem um perfeito manual do entusiasmo que viceja e prolifera em ambientes religiosos eletrizados pela emoção. Entretanto, tal como teve uma ascensão meteórica, Gantry sofre queda retumbante. Apanhado e denunciado publicamente pelo seu passado tortuoso, Gantry, em um gesto de aparente arrependimento, despede-se de sua benévola congregação com um refrão que o acompanha por toda parte: "E o que é o amor? / O amor é a estrela da manhã e do anoitecer. / Assim, cantem o amor de Deus!".

Desviando o enfoque do entusiasmo da Filosofia e da Teologia para a Psicologia, nota-se uma quase completa omissão por parte de psicólogos em lidar com o construto entusiasmo. William James, cujo "The Varieties of Religious Experience" (As Variedades da Experiência Religiosa) teve uma influência poderosa no contexto da Psicologia americana, foi lacônico a seu respeito. Sua visão diverge da de Shaftesbury, Hume e Taylor, já que ele julga o entusiasmo legítimo e o associa à experiência de conversão (JAMES, 1958).

Resumindo o pensamento de filósofos, teólogos e psicólogos dos três séculos passados com relação ao entusiasmo, pode-se afirmar que: ele é, primeiro, uma condição emocional, consequentemente emergindo das camadas mais profundas da natureza humana; segundo, ele é frequentemente associado ao contexto religioso; e, por último, provavelmente esteja exposto à manipulação e à mistificação.

Embora afetado por suspeita e crítica, não há como contestar que entusiasmo é uma condição íntima. Ele pode manifestar-se por meio de uma variedade de movimentos e gestos - por exemplo, emoções faciais, o fixar do olhar para pessoas da audiência -, porém estes não podem existir à parte de condições interiores.

O que se pode aprender das perspectivas filosófica, teológica e psicológica com potencial de elucidar o entusiasmo docente? Ainda, o que haveria em comum entre o entusiasmo tal como observado nos seus protagonistas nos templos e aqueles das salas de aula? O que discrepa neles? 


\section{O empírico}

A dimensão subjetiva tornou-se saliente no estudo encetado por Monteiro (2003), no qual ela utilizou a metodologia de mixed methods (métodos mistos) - uma combinação de aproximações quantitativa (questionário) e qualitativa (entrevista). Seu estudo foi conduzido entre concluintes de dois cursos de graduação de uma universidade privada do Centro-Oeste: um curso da área de Humanas e o outro da área de Exatas.

Monteiro utilizou dois procedimentos na sua pesquisa que não haviam sido empregados em estudos precedentes: um foi a técnica do incidente crítico (FLANAGAN, 1954) e o outro foi a identificação nominal do professor entusiasmado pelo estudante respondente do questionário. Uma vez que esse estudante era concluinte, ele teria sido exposto ao maior número possível de professores no seu curso. Os professores identificados como entusiasmados foram entrevistados por Monteiro, sendo que o protocolo da entrevista espelhava o questionário respondido pelos estudantes, permitindo a ela detectar congruências e discrepâncias entre as duas fontes de informação. Os incidentes críticos foram obtidos dos estudantes.

Os dados dos questionários desvelaram associações importantes, por exemplo: a frequência dos professores entusiasmados, indicados pelos alunos; e o número de vezes que eles ensinaram determinadas disciplinas que não evidenciaram uma relação linear. Diferentemente, a associação entre as duas variáveis retratou uma curva "U" invertida, indicando seu ápice no número de vezes em que a disciplina foi lecionada, reduzindo-se daí em diante o número de professores entusiasmados.

Além disso, os incidentes críticos se constituíram em uma fonte de novos elementos e circunstâncias na definição do entusiasmo docente. Um desses elementos, que surgem nos professores entusiasmados, foi a forma rigorosa como eles tratavam a turma, relatada nos incidentes críticos. Alguns achados e procedimentos no estudo de Monteiro foram incorporados na investigação conduzida em 2009, especificamente itens do questionário, relatos dos incidentes críticos e indicação nominal dos professores entusiasmados (RODRIGUES JUNIOR; PASQUALI; MOURA, 2009). Este último estudo está sumariado a seguir.

Um total de 457 estudantes, de seis cursos de nove Instituições de Educação Superior do Centro-Oeste brasileiro, respondeu a um questionário, cujo foco era o professor entusiasmado. O instrumento consistia de 29 itens, dos quais 5 centrados em dados demográficos e 24 em afirmações, de acordo com escala de Likert de cinco alternativas.

As afirmações eram fundamentadas em incidentes críticos, originários da dissertação de Monteiro (2003). Uma dessas afirmações era "Podia-se ver que seu entusiasmo resultava do seu domínio do conteúdo; essa pessoa era, de fato, um conhecedor do assunto". O instrumento utilizado na pesquisa está no Anexo. 
Os dados obtidos foram submetidos à análise fatorial, método estatístico adequado à redução de numerosas variáveis a poucos compostos denominados fatores (KIM; MUELLER, 1981; PASQUALI, 1999; COSTELLO; OSBORNE, 2005). Três fatores emergiram da análise, escalonados por sua importância: (1) respeitoso e sábio; (2) comprometido e exigente; e (3) informal. Os três fatores confluem no delineamento do professor universitário entusiasmado; explicitando, um professor universitário seria percebido pelos estudantes como entusiasmado dependendo de diferentes combinações dos três fatores nele imanentes. Da mesma forma, esses fatores indicam que o entusiasmo docente retrocede a causas mais profundas do que a exteriorização de gestos.

Esses dados tratados mediante a metodologia mista, na qual o quantitativo foi posto vis-à-vis com o qualitativo, permitiram aos pesquisadores compor um modelo com razoável número de componentes do entusiasmo docente. Esse modelo é integrado por três ordens de componentes, apresentadas na Figura. Como se pode ver, a primeira ordem é integrada pelos fatores oriundos da análise quantitativa dos dados, portanto com fundamentação adequada; as demais elipses apresentam, respectivamente, componentes que necessitam de aprofundamento na investigação e componentes de importância periférica em relação ao construto. $\mathrm{O}$ modelo proposto pode ser útil a pesquisadores que desejem explorar o construto no futuro.

Figura. Modelo empírico para o estudo do professor entusiasmado.

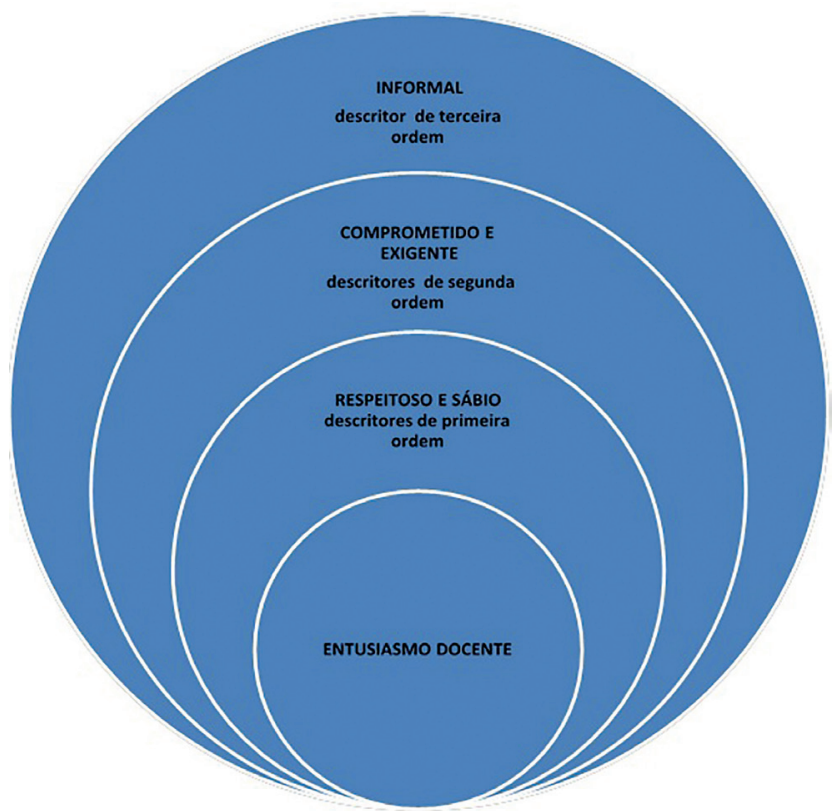

Fonte: elaborada pelos autores. 


\section{Considerações finais}

No início deste artigo, teve-se por intenção apresentar argumentos dando sustentação ao entendimento de que o entusiasmo docente, aquele manifestado pelos docentes universitários, é um construto cujas raízes se assentam nos estratos profundos da natureza humana. Essa posição vai de encontro àquilo que tem sido pesquisado desde a década de 1960 até agora. Um grande número de estudos, indicados neste trabalho, toma como pressuposto que gestos, realizados pelo professor durante a instrução, constituem a essência do entusiasmo docente.

A posição deste texto fundamentou-se em três ordens de argumentos: (1) o etimológico, (2) o filosófico-teológico e (3) o empírico. Cada argumento foi apresentado e exposto. O último argumento resulta de um estudo conduzido nos anos 2008-2009 (RODRIGUES JUNIOR; PASQUALI; MOURA, 2009), cujos dados evidenciaram que o entusiasmo do professor universitário é proveniente de uma combinação de três fatores: primeiro, respeitoso e sábio; segundo, comprometido e exigente; e terceiro, informal.

Atentando-se para o apelo de Ball (2012) para que a pesquisa redunde no incremento da educação, o que pode ser dito acerca do professor entusiasmado na academia contemporânea? Primeiro, como visto, professores entusiasmados não podem ser "produzidos"; eles são formados desde o nascimento e por meio da trajetória pessoal. Portanto, não faz sentido treinar docentes para que se tornem entusiasmados em sala de aula. Segundo, professores entusiasmados podem ser identificados e apoiados. A vitalidade desse indivíduo pode ter um impacto inestimável no ambiente universitário.

Cabe, a esse ponto, uma explicação sobre o título do presente texto. Por que representar o professor entusiasmado como uma espécie ameaçada de extinção? Não seria essa uma representação a um só tempo pessimista e exagerada? Infelizmente, dados e ocorrências verificados ao longo da pesquisa convencem de que o professor entusiasmado, a despeito da importância que possa ter no contexto educacional, constitui-se, não poucas vezes, em um "estranho no ninho". Dois registros materializam isso.

Primeiro, ao procurar instituições ou cursos nos quais se pudesse aplicar o questionário de pesquisa, uma delas - um curso de Medicina de uma IES pública federal - recusou sua participação. A razão alegada foi que, ao solicitar que o respondente do questionário identificasse nominalmente o professor entusiasmado, esse procedimento iria, com elevada probabilidade, criar uma linha demarcatória entre professores percebidos como entusiasmados e os demais, não possuidores dessa qualidade, o que, em decorrência, suscitaria mal-estar dentro do corpo docente. 
Um segundo registro torna o título do artigo mais do que especulação. Dois professores entusiasmados com maior número de indicações em diferentes cursos e instituições relataram em entrevista que sofreram críticas de colegas e pressão de suas instituições pelo fato de serem e agirem em sala de aula diferentemente dos demais. Ambos, ao cabo de poucos anos, foram dispensados de suas instituições (privadas, ambas), a despeito de gozarem de elevada reputação como docentes por seus alunos.

Finalmente, concorda-se que o estudo do entusiasmo docente não é simples por causa da natureza complexa do construto. A contribuição deste artigo não é, definitivamente, conclusiva; espera-se, contudo, que ela propicie maior entendimento acerca do dessa importante característica de professores.

Recebido em: 12/07/2019

Aceito para publicação em: 23/08/2019

\section{Notas}

1 Doutoranda em Educação pela Universidade Católica de Brasília (UCB). Possui mestrado em Educação pela UCB e MBA em Gestão Educacional. Tem experiência nas áreas de docência, coordenação pedagógica, orientação educacional, gestão educacional, educação a distância, produção de material didático, tutoria e revisão textual, seja na Educação Básica, seja no Ensino Superior. Atua na área de gestão de pessoas na Diretoria de Capacitação do Instituto Federal de Brasília. E-mail: veras.sonia@gmail.com

2 Possui graduação, mestrado e doutorado em Psicologia pela Universidade de Brasília (UnB). É professora do Departamento de Psicologia Clínica da UnB, do Programa de Pós-Graduação em Psicologia Social, do Trabalho e das Organizações e é coordenadora do curso de graduação em Psicologia da UnB. Atuou como assistente técnica em perícias de Avaliação Psicológica pela União e na elaboração de Análise Profissiográfica (estudo científico do cargo) e Mapeamento de Competências em Segurança Pública no Brasil. Trabalha na área de avaliação psicológica. É coordenadora do Grupo de Pesquisa em Avaliação Psicológica em Segurança Pública e Privada, fundado em 2009. Atualmente, coordena o Laboratório de Pesquisa em Avaliação e Medida (LabPAM/UnB). É psicometrista, com experiência em construção e validação de testes, escalas e outras medidas psicológicas, em seleção de pessoal (pública e privada) e gestão de pessoas. E-mail: crisfaiad@gmail.com

3 Mestre em Educação pelo Programa de Pós-Graduação Stricto Sensu da Universidade Católica de Brasília (UCB). Licenciada em Pedagogia pela Faculdade Albert Einstein de Brasília. Graduada em Relações Internacionais pela Universidade Católica de Goiás. Atualmente, leciona no curso de Pedagogia do Centro Universitário UniProjeção e na Pós-Graduação em Educação do Centro de Aprendizagem e Aperfeiçoamento Profissional Superior em Brasília (CAAPS). E-mail: jaquelinefrodrigues@hotmail.com

4 Mestrado em Psicologia Social, do Trabalho e das Organizações pela Universidade de Brasília (UnB). Especialista socioeducativo e psicólogo da Secretaria de Justiça e Cidadania. E-mail: tatiana.moreira@gmail.com

5 Mestre e doutor pela Emory University, em Atlanta, Georgia, Estados Unidos. Nos últimos 20 anos foi professor da Universidade de Brasília (UnB) e da Universidade Católica de Brasília (UCB). Membro da American Educational Research Association desde 1980. Publicou cinco 
livros na área de Educação, particularizando a capacitação de docentes da Educação Superior. E-mail: florenciomeister@gmail.com

6 Tradução nossa: "Porém meu objetivo é interpretar o entusiasmo, não criticá-lo. Se pudéssemos interpretá-lo corretamente, deveríamos agarrar-nos a um ponto mais do que a qualquer outra coisa - em sua essência o entusiasmo não é uma tendência errônea, mas uma ênfase equivocada”.

\section{Referências}

ARNDT, William; GINGRICH, F. Wilbur. A greek-english lexicon of the New Testament and other early Christian literature. Chicago: The University of Chicago Press, 1959.

BALL, Arnetha. To know is not enough: Knowledge, power, and the zone of generativity. Educational Researcher, v. 41, n. 8, p. 283-293, 2009. Disponível em: https://journals.sagepub.com/doi/abs/10.3102/0013189x12465334. Acesso em: 13 jan. 2019.

BARNES, Laura; BARNES, Michael. Academic discipline and generalizability of student evaluations of instruction. Research in Higher Education, v. 34, n. 2, p. 135-149, 1993. Disponível em: https://link.springer.com/article/10.1007/BF00992160. Acesso em: 8 abr. 2019.

BETTENCOURT, Edward et al. Effects of teacher enthusiasm training on student on-task behavior and achievement. American Educational Research Journal, v. 20, n. 3, p. 435-450, 1983. Disponível em: https://psycnet.apa.org/ record/1984-10697-001. Acesso em: 12 jun. 2019.

COFFMAN, William E. Determining students' concepts of effective teaching from their ratings of instructors. Journal of Educational Psychology, v. 45, n. 5, 277-286, 1954. Disponível em: https://psycnet.apa.org/record/1955-03065-001. Acesso em: 12 jun. 2019.

COSTELLO, Anna B; OSBORNE, Jason W. Best practices in exploratory fator analysis: Four recommendations for getting the most from your analysis. Practica Assessment, Research \& Evaluation, v. 10, n. 7, p. 1-9, jul. 2005.

DILLON, John .A classification of research questions. Review of Educational Research, v. 54, n. 3, p. 327-361, 1984. Disponível em: https://www. jstor.org/stable/1170452?seq=1\#page_scan_tab_contents. Acesso em: 10 jun. 2019.

ELMER GANTRY. Direção: Richard Brooks. Produção: Bernard Smith. Los Angeles: MGM, 1960.

FANCHON F. Funk et al. The cooperating teacher as most significant other: a competent humanist. Action in Teacher Education, v. 4, n. 2, p. 57-64, 1982. 
Disponível em: https://www.tandfonline.com/doi/abs/10.1080/01626620.198 2.10519106. Acesso em: 10 jun. 2019.

FLANAGAN, John. The critical incident technique. Psychological Bulletin, v. 31, n. 4, p. 327-358, 1954. Disponível em: https://psycnet.apa.org/doiLanding?doi=10.1037\%2Fh0061470. Acesso em: 5 abr. 2019.

HUME, David. The philosophical works. v. 2. London: Scientia Verlag Aalen, 1964.

JAMES, William. The varieties of religious experience. New York: Mentor Books, 1958.

KELLER, Melanie et al. Teacher enthusiasm: Reviewing and redefining a complex construct. Educational Psychology Review, v. 28, n. 4, p. 743-769, 2015. Disponível em: https:/ /link.springer.com/article/10.1007/s10648-0159354-y. Acesso em: 12 abr. 2019.

KIERKEGAARD, Sören. The difficulty of being Christian. Notre Dame, Indiana: University of Notre Dame Press, 1968.

KIM, Jae-On; MUELLER Charles. Factor analysis: statistical methods and practical issues. Beverly Hills: Sage Publications, 1981.

KNOX, Ronald. Enthusiasm: A chapter in the history of religion. New York: Oxford University Press, 1950.

KUNTER, Mareike et al. Teacher enthusiasm: Dimensionality and context specificity. Contemporary Educational Psychology, v. 36, n. 4, p. 289-301, 2011. Disponível em: https://eric.ed.gov/?id=EJ939487. Acesso em: 23 jun. 2019.

LEWIS, Sinclair. Elmer Gantry. San Diego: Harcourt Trade Publishers, 1927.

LI, Rose Yanhong; KAYE, Mike. A case study for comparing two service quality measurement approaches in the context of teaching in higher education. Quality in Higher Education, v. 4, n. 2, p. 103-113, 1998. Disponível em: https://www.tandfonline.com/doi/abs/10.1080/1353832980040202. Acesso em: 5 maio 2019.

MASTIN, Victor. Teacher enthusiasm. The Journal of Educational Research, v. 56, n. 7, p. 385-386, 1963. Disponível em: https://www.tandfonline. com/doi/abs/10.1080/00220671.1963.10882963. Acesso em: 5 maio 2019.

McKINNEY, C. Warren et al. Some effects of teacher enthusiasm on student achievement in fourth grade social studies. Journal of Educational Research, v. 76, n. 4, p. 249-253, mar./apr. 1982. Disponível em: https://www. tandfonline.com/doi/abs/10.1080/00220671.1983.108854602963. Acesso em: 5 maio 2019. 
MONTEIRO, Simone Maria. O professor universitário entusiasmado: um estudo qualitativo-quantitativo de características do construto. 2003. Dissertação (Mestrado em Educação) - Universidade Católica de Brasília, Brasília, 2003.

MURPHY, Cheryl; WALLS, Richard. Concurrent and sequential occurrences of teacher enthusiasm behaviors. In: ANNUAL MEETING OF THE AMERICAN EDUCATIONAL RESEARCH ASSOCIATION, 1984, New Orleans. Paper presented... New Orleans, 1984.

NEILSON William (Ed.). Webster's new international dictionary of the English language. 2. ed. Springfield: G.C. Merriam Company Pub, 1947.

ONWUEGBUZIE, Anthony et al. Students' perceptions of characteristics of effective college teachers: a validity study of a teaching evaluation form using a mixed-methods analysis. American Educational Research Journal, v. 44, n. 1, p. 113-160, 2007. Disponível em: . Acesso em: https://journals. sagepub.com/doi/abs/10.3102/0002831206298169?journalCode=aera. 10 jun. 2019.

OROSZ, Gábor et al. Teacher enthusiasm: A potential cure of academic cheating. Frontiers in Psychology, v. 6, p. 1-12, 2015. Disponível em: https:/ / www.academia.edu/20628783/Teacher_enthusiasm_a_potential_cure_of_academic_cheating. Acesso em: 15 abr. 2019.

PASQUALI, Luiz. Testes referentes a construto: teoria e modelo de construção. In: _. (Org.). Instrumentos psicológicos: manual prático de elaboração. Brasília: Laboratório de Pesquisa em Avaliação e Medida, 1999. p. 37-71.

PATRICK, Brian; HINSLEY, Jennifer; KEMPLER, Toni. "What's everybody so excited about?: The effects of teacher enthusiasm on student intrinsic motivation and vitality. The Journal of Experimental Education, v. 68, n. 3, p. 217-236, 2000. Disponível em: https://www.tandfonline.com/doi/ abs/10.1080/00220970009600093. Acesso em: 5 maio 2019.

PERELMAN, Chaim. Traité de l'argumentation. Bruxelles: Éditions de l’Université de Bruxelles, 1988.

RODRIGUES JUNIOR José Florêncio; PASQUALI, Luiz; MOURA, Cristiane Faiad de. Dimensões do construto entusiasmo como percebido em professores universitários. Avaliação Psicológica, v. 8, n. 3, p. 391-403, 2009. Disponível em: http://pepsic.bvsalud.org/pdf/avp/v8n3/v8n3a11.pdf. Acesso em: 10 fev. 2019.

RYANS, David. Characteristics of teachers. Washington, DC: American Council on Education, 1970. 
SHAFTESBURY, Anthony Ashley Cooper, 3rd earl of. Characteristics of Men, Manners, Opinions, Times. Cambridge: Cambridge University Press, 1999.

SOUZA, Carlos Alberto Lopes de et al. No balanço do entusiasmo: Reconhecendo oscilações manifestadas em professores universitários entusiasmados. In: FAIAD, Cristiane et al. $\mathbf{O}$ professor universitário entusiasmado: seis estudos sobre uma espécie em extinção. Brasília: Edição do Autor, 2014.

TAYLOR, Isaac. Natural history of enthusiasm. London: Holdsworth \& Ball, 1834.

WINEBURGH, Adele. The effect of enthusiastic teaching on the listening comprehension of kindergarten children. 1990. Dissertação (Mestrado) - Mercer University, Atlanta, 1990.

WOOD, Andrea; MURRAY, Harry. Effects of teacher enthusiasm on student attention, motivation, and memory encoding. In: THE ANNUAL MEETING OF THE AMERICAN EDUCATIONAL RESEARCH ASSOCIATION, 1999, Montreal, Canada. Paper presented... Montreal, 1999.

YOUNG, Edith M. Effect of teacher enthusiasm on vocational business education: student achievement. 1973. Tese (Doutorado) - University of Missouri, Columbia, 1973.

\section{ANEXO}

\section{Escala de Avaliação do Professor Entusiasmado (EAPE)}

\section{Um Professor Entusiasmado}

Você está concluindo sua graduação. Teve mais de uma dezena de professores lecionando diferentes disciplinas. Pois bem, peço identificar um deles que lhe tenha chamado atenção por ter sido entusiasmado(a) ao ministrar sua disciplina.

A seguir, apresento-lhe algumas proposições que se aplicam ou não a esse(a) professor(a). Anexo a cada proposição ou enunciado vem uma sequência de alternativas que representam sua percepção sobre essa pessoa. Elas variam entre concordo fortemente e discordo fortemente. Marque com um x a que melhor caracterizar aquele(a) professor(a). Peço assinalar todas as proposições, mesmo quando não estiver inteiramente $\operatorname{seguro(a)~na~sua~percepção.~}$

Asseguramos a anonimidade de suas respostas. Ou seja, os dados serão tratados coletivamente, não individualmente. 
Antes do questionário propriamente dito, peço fornecer algumas informações sobre você e sobre o professor em questão.

\section{Dados sobre você}

01. Instituição onde estuda:

02. Sexo: ( ) feminino ( ) masculino

03. Curso de que é aluno(a):

04. Faixa etária: ( ) entre 20 e 24 anos ( ) entre 25 e 29 anos

( ) mais de 30 anos

\section{Dados sobre o(a) professor(a)}

05. Sexo: ( ) feminino ( ) masculino

Acrescentaria bastante à análise dos dados se lhe fosse possível registrar o nome do(a) professor(a) entusiasmado(a) a que você se refere.

Nome do(a) professor(a):

\section{Suas percepções sobre o(a) professor(a) entusiasmado(a)}

Por favor, assinale com um x, no parêntese correspondente, a alternativa que melhor representa sua percepção.

Agradecemos muito sua colaboração. Se tiver interesse em receber os resultados deste estudo, forneça, a seguir, seu e-mail:

06. Na minha percepção esse(a) professor(a) acreditava que valores como honestidade, trabalho, respeito ao próximo, deveriam orientar as ações dos indivíduos. ( ) Concordo fortemente

( ) Concordo

( ) Em dúvida/Não se aplica

( ) Discordo

( ) Discordo fortemente

07. Não se podia ter certeza de quando ele(a) viria para aula com boa disposição.
( ) Concordo fortemente
( ) Concordo
( ) Em dúvida/Não se aplica
( ) Discordo
( ) Discordo fortemente

08. $\mathrm{O}$ (a) professor(a) entusiasmado(a) que tenho em mente não faltava à aula à toa.
( ) Concordo fortemente
( ) Concordo
( ) Em dúvida/Não se aplica
( ) Discordo
( ) Discordo fortemente 
09. Bom(boa) professor(a), mas meio boa-vida. Horário para ele(a) não valia.
( ) Concordo fortemente
( ) Concordo
( ) Em dúvida/Não se aplica
( ) Discordo
( ) Discordo fortemente

10. Em sala de aula ou fora dela, era sempre uma pessoa entusiasmada.
( ) Concordo fortemente
( ) Concordo
( ) Em dúvida/Não se aplica
( ) Discordo
( ) Discordo fortemente

11. Às vezes, por causa do seu entusiasmo, ele(a) falava conosco sério, quase em um tom de repreensão.
( ) Concordo fortemente
( ) Concordo
( ) Em dúvida/Não se aplica
( ) Discordo
( ) Discordo fortemente

12. A aula desse(a) professor(a) não tinha muita variedade. Ele(a) dava aula expositiva usando quadro de giz ou retroprojetor e só, tal como os outros.
( ) Concordo fortemente
( ) Concordo
( ) Em dúvida/Não se aplica
( ) Discordo
( ) Discordo fortemente

13. Exercícios, provas e tarefas eram sempre revisados em sala de aula por esse(a) professor(a). Gastava tempo corrigindo erros que cometíamos.
( ) Concordo fortemente
( ) Concordo
( ) Em dúvida/Não se aplica
( ) Discordo
( ) Discordo fortemente

14. Embora entusiasmado(a), as notas/menções da turma eram geralmente baixas.
( ) Concordo fortemente
( ) Concordo
( ) Em dúvida/Não se aplica
( ) Discordo
( ) Discordo fortemente

15. Fora da sala de aula era uma múmia; porém, em sala de aula, era como um vulcão em atividade.
( ) Concordo fortemente
( ) Concordo
( ) Em dúvida/Não se aplica
( ) Discordo
( ) Discordo fortemente

16. Podia-se ver que o entusiasmo era resultado do quanto ele(a) sabia a matéria. Era mesmo um(a) "expert" no assunto.
( ) Concordo fortemente
( ) Concordo
( ) Em dúvida/Não se aplica
( ) Discordo
( ) Discordo fortemente 
17. Junto com o conteúdo das aulas, esse(a) professor(a) nos passava a convicção de que vale a pena ser honesto, esforçado, respeitador do próximo.
( ) Concordo fortemente
( ) Concordo
( ) Em dúvida/Não se aplica
( ) Discordo
( ) Discordo fortemente

18. Cortês. Sempre nos cumprimentava ao entrar em sala e ao sair, ou mesmo quando nos encontrava fora da classe.
( ) Concordo fortemente
( ) Concordo
( ) Em dúvida/Não se aplica
( ) Discordo
( ) Discordo fortemente

19. Trazia textos novos, interessantes para a sala e nos estimulava a lê-los.
( ) Concordo fortemente
( ) Concordo
( ) Em dúvida/Não se aplica
( ) Discordo
( ) Discordo fortemente

20. Era um tipo meio reservado(a). Concentrava-se na aula e não interagia muito conosco.
( ) Concordo fortemente
( ) Concordo
( ) Em dúvida/Não se aplica
( ) Discordo
( ) Discordo fortemente

21. Sentava-se à mesa e ali se mantinha durante todo o tempo da aula.
( ) Concordo fortemente
( ) Concordo
( ) Em dúvida/Não se aplica
( ) Discordo
( ) Discordo fortemente

22. Em pouco tempo sabia o nosso nome de cor.
( ) Concordo fortemente
( ) Concordo
( ) Em dúvida/Não se aplica
( ) Discordo
( ) Discordo fortemente

23. Estimulava-nos a dar o melhor de nós na disciplina.
( ) Concordo fortemente
( ) Concordo
( ) Em dúvida/Não se aplica
( ) Discordo
( ) Discordo fortemente

24. Não havia hora para começar ou terminar a aula.
( ) Concordo fortemente
( ) Concordo
( ) Em dúvida/Não se aplica
( ) Discordo
( ) Discordo fortemente

25. O entusiasmo compensava a deficiência de conhecimento da disciplina.
( ) Concordo fortemente
( ) Concordo
( ) Em dúvida/Não se aplica
( ) Discordo
( ) Discordo fortemente 
26. Mais para tímido(a) do que para eufórico(a); quase nunca nos fitava.
( ) Concordo fortemente
( ) Concordo
( ) Em dúvida/Não se aplica
( ) Discordo
( ) Discordo fortemente

27. Mesmo quando errávamos, ele(a) nos corrigia com boa disposição.

( ) Concordo fortemente ( ) Concordo ( ) Em dúvida/Não se aplica

( ) Discordo

( ) Discordo fortemente

28. Não apenas conhecia bem a matéria, mas tinha familiaridade com outros domínios do conhecimento.
( ) Concordo fortemente
( ) Concordo
( ) Em dúvida/Não se aplica
( ) Discordo
( ) Discordo fortemente

29. Penso que, por causa dos seus pontos de vista, alguns dos seus colegas não se davam bem com ele(a).

( ) Concordo fortemente

( ) Concordo ( ) Em dúvida/Não se aplica

( ) Discordo

( ) Discordo fortemente 